\title{
Neutrophils to Lymphocytes Ratio is an Easy Non Expensive Marker of Inflammation in Hemodialysis Patients
}

\author{
Abdelbassit Shaarawy ${ }^{1}$, Aber Halim Baki ${ }^{1}$, Nahla Mohamed Teama ${ }^{1 *}$, Rania M Abdel Halim ${ }^{2}$, Noha \\ Alaa Eldin Fahim ${ }^{2}$ and Reem Ahmed Sultan ${ }^{1}$ \\ ${ }^{1}$ Department of Internal Medicine and Nephrology, Faculty of Medicine, Ain Shams University, Egypt \\ ${ }^{2}$ Department of Clinical Pathology, Faculty of Medicine, Ain Shams University, Egypt
}

*Corresponding author: Nahla Mohamed Teama, Department of Internal Medicine and Nephrology, Faculty of Medicine, Ain Shams University, Egypt, Tel: 01090447009; E-mail: nahlateama25@gmail.com

Received date: November 23, 2018; Accepted date: December 11, 2018; Published date: December 14, 2018

Citation: Shaarawy A, Baki AH, Teama NM, Halim RMA, Fahim NAE, et al. (2018) Neutrophils to Lymphocytes Ratio is an Easy Non Expensive Marker of Inflammation in Hemodialysis Patients. J Clin Exp Nephrol Vol.3 No.4: 19. DOI: 10.21767/2472-5056.100070

Copyright: (C2018 Shaarawy A, et al. This is an open-access article distributed under the terms of the Creative Commons Attribution License, which permits unrestricted use, distribution, and reproduction in any medium, provided the original author and source are credited.

\section{Abstract}

Background: Patients with end stage renal disease (ESRD) have elevated levels of inflammatory mediators including Creactive protein (CRP), tumor necrosis factor- $\alpha$ (TNF- $\alpha$ ), and interleukin-6 (IL-6). Neutrophil to lymphocyte ratio was introduced as a novel inexpensive indicator that reflects the severity and extension of systemic inflammation and atherosclerosis, and predicts adverse clinical outcomes in cardiac and non-cardiac disorders including ESRD.

The aim of this study is to evaluate the frequency of subclinical inflammation using neutrophil to lymphocyte ratio (NLR) and its relation to other biochemical parameters in ESRD patients on maintenance haemodialysis (HD) in comparison to high-sensitivity C-reactive protein (hsCRP).

Methods: A cross sectional observational study including 100 clinically stable ESRD patients on regular haemodialysis (mean age $48.25 \pm 13.67,57 \%$ were males), NLR was calculated from complete blood count and hsCRP was recorded for all patients where $8.2 \mathrm{mg} / \mathrm{L}$ indicated inflammation.

Results: NLR was positively correlated to hsCRP, using ROC curve ( $A \cup C=0.647$ ) and the best cut off point to detect subclinical inflammation in HD patients was calculated with NLR greater than or equal 1.54 , with sensitivity $68.25 \%$ and specificity $54 \%$. By using univariate and multiple variate analysis in our work to test for independent predictors of hsCRP levels as an indicator for inflammation, it was found that NLR can be used as an independent predictor of hSCRP as an inflammatory marker, with statistically significant correlation $(p=0.015)$. Spearman coefficient $(r s=0.220)$ shows statistically significant $(p=0.028)$ positive correlation between NLR and hsCRP.

Conclusion: NLR is an easy, simple and non-expensive method that can be used as a marker of inflammation in HD patients when compared to hsCRP.
Keywords: hsCRP; Inflammation in HD; Neutrophil-tolymphocyte ratio

\section{Introduction}

End stage renal disease (ESRD) patients on regular hemodialysis (HD) have higher rates of mortality and morbidity compared to general population. The total life expectancy of a patient with ESRD is only one-fourth to one-fifth that of the general population [1].

Cardiovascular diseases (CVD) are considered to be the commonest cause of mortality, followed by infections and septicemia as the second most common [2].

Both cardiovascular and infectious causes of death are associated with a state of chronic inflammation. Chronic inflammation, a key factor in the pathogenesis of atherosclerosis, is increased in ESRD patients compared to normal population. It is predicted that early and specific detection of inflammation might improve the quality of life of those patients and decrease rate of mortality and morbidity [3].

Patients with ESRD have elevated serum levels of inflammatory mediators including C-reactive protein (CRP), interleukin (IL)- 6 and tumor necrosis factor- $\alpha$ (TNF- $\alpha$ ), as it has been shown that they play a central role in the vicious circle of malnutrition, inflammation, and atherosclerosis and increase risk for cardiovascular events and overall mortality in ESRD patients [4].

Leukocytes are considered the classic inflammatory markers, due to their central role in the development of atherosclerosis and its complications by mediating several biochemical pathways [4].

It was found that increased neutrophil count was strongly associated with malnutrition and inflammation, and that decreased lymphocyte count had a weaker association. Increased neutrophils and decreased lymphocytes were also an independent predictor of mortality in HD patients [3]. 
Neutrophil to lymphocyte ratio (NLR) was introduced as a novel inexpensive and readily available indicator that reflects the severity and extension of systemic inflammation and atherosclerosis, and predicts adverse clinical outcomes, and estimates survival in cardiac and non-cardiac disorders including ESRD [5]

The neutrophil-to-lymphocyte ratio (NLR), calculated by dividing the absolute neutrophil count by the absolute lymphocyte count, is a marker of poor prognosis in several disorders such as malignancies, chronic kidney disease, and myocardial infarction [3].

Neutrophil-lymphocyte ratio (NLR) is increasingly recognized as a possible marker of systemic inflammation in HD patients, but its prognostic value is unknown [6].

Therefore, the present study was designed to evaluate the NLR in relation to a measure of inflammation, namely the highsensitivity C-reactive protein (hsCRP) in ESRD patients on maintenance hemodialysis.

\section{Materials and Methods}

\section{Study population}

This study is a cross sectional study that included 100 clinically stable adult ESRD patients on regular hemodialysis for more than 6 months, with native arteriovenous fisula (AV) fistula, randomly selected from haemodialysis units in Ain-Shams University hospitals (mean age $48.25 \pm 13.67,57 \%$ were males). All patients received conventional hemodialysis, three sessions per week, four hours long each, using standard dialysate containing bicarbonate and biocompatible low flux HD polysolfon membrane; surface area $1.4 \mathrm{~m}^{2}$ and heparin as anticoagulant.

Patients with the following conditions were excluded; fever or acute infectious diseases, chronic bacterial infections. (e.g. TB, etc.), evident signs and symptoms of active inflammation (e.g. arthritis, gouty arthritis, etc.), known autoimmune disorders (SLE, Vasculitis, etc.), patients who had a failed renal transplant and returned to hemodialysis, known malignancies, patients using steroids or other immunosuppressive therapies, decompensated heart failure, $\mathrm{EF}<30 \%$, chronic liver disease (Child B,C) and lung diseases.

\section{Study parameters}

Patients' demographic data (age, sex), BMI $\left(\mathrm{kg} / \mathrm{m}^{2}\right)$, blood pressure, duration of HD in years, etiology of renal failure and other comorbidities were obtained.

\section{Laboratory assessment}

Complete blood count with differential.

Serum creatinine, blood urea nitrogen (BUN), serum sodium (Na) and serum potassium (K). Corrected serum calcium, phosphate, parathyroid hormone (PTH).
Serum iron, ferritin, total iron binding capacity (TIBC).

Lipid profile; low density lipoprotein (LDL), triglycerides, total cholesterol.

Adequacy of hemodialysis was measured by Urea reduction ratio (URR) URR $=100 \% \times$ (predialysis BUN-postdialysis BUN)/ predialysis BUN [7].

NLR and hsCRP were recorded for all patients.

Neutrophils to lymphocytes ratio was calculated by dividing absolute neutrophil count by absolute lymphocyte count.

High-sensitivity C-reactive protein was measured by high sensitivity enzyme immunoassay test kit, with expected range of $68-8200 \mathrm{ng} / \mathrm{ml}$ in healthy adults.

\section{Statistical methods}

Data were fed to the computer and analyzed using IBM SPSS software package version 20.0. (Armonk, NY: IBM Corp).

Data were described using range (minimum and maximum), mean, standard deviation and median for parametric numerical data. Qualitative data were described using number and percent. Quantitative significance of the obtained results was judged at the $5 \%$ level.

The Kolmogorov-Smirnov test was used to verify the normality of distribution. Wilcoxon signed ranks test was used for abnormally distributed quantitative variables, to compare between two periods. Spearman coefficient was used to correlate between two distributed abnormally quantitative variables. Mann Whitney test was used for abnormally distributed quantitative variables, to compare between two studied groups. Receiver operating characteristic curve (ROC) is generated by plotting sensitivity (TP) on $Y$ axis versus 1specificity (FP) on $X$ axis at different cut off values. The area under the ROC curve denotes the diagnostic performance of the test. Area more than $50 \%$ gives acceptable performance and area about $100 \%$ is the best performance for the test. The ROC curve allows also a comparison of performance between two tests. Chi-square test is for categorical variables, to compare between different groups. Fisher's Exact or Monte Carlo correction is a correction for chi-square when more than $20 \%$ of the cells have expected count. Student t-test is for normally distributed quantitative variables, to compare between two studied groups. Univariate and multivariate regression is to detect the most independent/affecting factor for hsCRP (ng/ml).

\section{Results}

This study contained $100 \mathrm{HD}$ patients, the median age of the studied patients was $48.25 \pm 13.67$ years and their age generally ranged between $19-80$ years; $57 \%$ were males while $43 \%$ were females; the median duration of dialysis in the studied patients was $5.97 \pm 4.61$ years and it generally ranged between 1-19 years. $29.0 \%$ of the studied participants had diabetes; $78.0 \%$ had HTN; $39.0 \%$ had positive viral markers (all were HCV positive, there were no HBV nor HIV positive patients); $3 \%$ has IHD; $5 \%$

Serum albumin. 
with cerebrovascular disease; $7 \%$ with osteoarthritis; $5 \%$ with COPD.

Table 1: Comparison between patients with and without subclinical inflammation according to hsCRP and different laboratory parameters.

\begin{tabular}{|c|c|c|c|}
\hline & \multicolumn{2}{|l|}{ hsCRP (ng/ml) } & \multirow[t]{2}{*}{$\mathbf{p}$} \\
\hline & $\begin{array}{l}\text { No } \\
\text { inflammation } \\
(n=37)\end{array}$ & $\begin{array}{l}\text { Inflammation } \\
(n=63)\end{array}$ & \\
\hline & \multicolumn{2}{|l|}{ Mean \pm SD } & \multirow[b]{2}{*}{$0.146^{*}$} \\
\hline $\mathrm{Hb}(\mathrm{g} / \mathrm{dl})$ & $10.34 \pm 2.16$ & $9.74 \pm 1.86$ & \\
\hline WBCs $(\times 103)$ & $5.63 \pm 1.82$ & $6.02 \pm 2.22$ & $0.363^{*}$ \\
\hline TSAT $(\%)$ & $30.50 \pm 13.58$ & $29.40 \pm 15.65$ & $0.332^{* *}$ \\
\hline TIBC (ug/dl) & $191.89 \pm 38.18$ & $\begin{array}{l}198.83 \\
38.21\end{array}$ & $0.383^{*}$ \\
\hline Ferritin (ng/ml) & $854.68 \pm 639.94$ & $\begin{array}{l}795.71 \\
541.75\end{array}$ & $0.980^{* *}$ \\
\hline Iron (ug/dl) & $56.86 \pm 24.41$ & $56.67 \pm 29.88$ & $0.655^{* *}$ \\
\hline PTH (Pg/ml) & $500.68 \pm 416.59$ & $\begin{array}{l}313.75 \\
197.60\end{array}$ & $0.047^{* *}$ \\
\hline Albumin (mg/dl) & $3.78 \pm 0.30$ & $3.80 \pm 0.41$ & $0.785^{*}$ \\
\hline PO4 (mg/dl) & $4.44 \pm 1.55$ & $4.30 \pm 1.35$ & $0.536^{*}$ \\
\hline Corrected $\mathrm{Ca}(\mathrm{mg} / \mathrm{dl})$ & $8.37 \pm 0.67$ & $8.28 \pm 0.73$ & $0.752^{*}$ \\
\hline Neutrophil & $2.81 \pm 1.12$ & $3.39 \pm 1.64$ & $0.102^{* *}$ \\
\hline Lymphocytes & $2.16 \pm 1.06$ & $1.97 \pm 0.85$ & $0.417^{\star *}$ \\
\hline $\mathrm{N} / \mathrm{L}$ ratio & $1.51 \pm 0.66$ & $1.97 \pm 1.04$ & $0.014^{* *}$ \\
\hline URR (\%) & $71.22 \pm 11.19$ & $71.88 \pm 9.51$ & $0.752^{*}$ \\
\hline $\begin{array}{l}\text { Urea } \\
(\mathrm{mg} / \mathrm{dl})\end{array}$ & $86.03 \pm 34.69$ & $87.63 \pm 31.71$ & $0.805^{\star *}$ \\
\hline $\begin{array}{l}\text { Urea } \\
(\mathrm{mg} / \mathrm{dl})\end{array}$ & $23.22 \pm 11.38$ & $23.13 \pm 8.58$ & $0.655^{* *}$ \\
\hline Cholesterol (mg/dl) & $193.81 \pm 27.02$ & $\begin{array}{l}202.03 \\
22.52\end{array}$ & $0.105^{*}$ \\
\hline LDL (mg/dl) & $101.65 \pm 32.69$ & $\begin{array}{ll}114.65 & \pm \\
27.43 & \end{array}$ & $0.036^{*}$ \\
\hline TGs (mg/dl) & $168.97 \pm 23.68$ & $\begin{array}{l}160.70 \\
29.73\end{array}$ & $0.129^{*}$ \\
\hline $\mathrm{Na}(\mathrm{mEq} / \mathrm{l})$ & $139.19 \pm 3.38$ & $137.46 \pm 3.62$ & $0.020^{*}$ \\
\hline $\mathrm{K}(\mathrm{mEq} / \mathrm{l})$ & $5.30 \pm 0.70$ & $5.43 \pm 0.54$ & $0.315^{*}$ \\
\hline \multicolumn{4}{|c|}{$\begin{array}{l}\text { "Student t-test for association between hsCRP (ng/ml) and different } \\
\text { parameters, }{ }^{*} \text { Mann Whitney test for association between hsCRP }(\mathrm{ng} / \mathrm{ml}) \text { and } \\
\text { different parameters, Highlighted values: Statistically significant at } \mathrm{p} \leq 0.05 \text {. }\end{array}$} \\
\hline
\end{tabular}

The etiology of CKD was due to diabetic nephropathy in one quarter of the patients $(25.0 \%) ; 17.0 \%$ was due to analgesic abuse, while $16.0 \%$ was due to hypertensive kidney disease, autosomal dominant polycystic kidney disease in $13 \%$, chronic pyelonephritis in $11.0 \%$, chronic glomerulonephritis in $9.0 \%$, pregnancy related in $5.0 \%$, chronic gout in $3.0 \%$ and amyloidosis in $1.0 \%$ patients.

(C) Under License of Creative Commons Attribution 3.0 License
The majority of the studied patients show adequate hemodialysis $(83.0 \%)$ as their URR was $65.0 \%$ or more. It was found that 63 patients (63\%) of studied population have subclinical inflammation, where hsCRP $>8200 \mathrm{ng} / \mathrm{ml}$ indicates the presence of inflammation despite absence of any overt signs and symptoms of inflammation and 37 patients (37\%) have $\mathrm{hsCRP}<8200 \mathrm{ng} / \mathrm{ml}$ which indicates the absence of inflammation (Table 1).

Table 2: Comparison between patients with and without subclinical inflammation according to NLR and laboratory parameters.

\begin{tabular}{|c|c|c|c|}
\hline & \multicolumn{2}{|l|}{ NLR } & \multirow[t]{2}{*}{$\mathbf{p}$} \\
\hline & $\begin{array}{l}\text { No inflammation } \\
(n=39)\end{array}$ & $\begin{array}{l}\text { Inflammation } \\
(n=61)\end{array}$ & \\
\hline & \multicolumn{2}{|l|}{ Mean \pm SD } & \multirow[b]{2}{*}{$0.193^{*}$} \\
\hline $\mathrm{Hb}(\mathrm{g} / \mathrm{dl})$ & $10.28 \pm 1.87$ & $9.75 \pm 2.04$ & \\
\hline WBCs $(\times 103)$ & $5.66 \pm 1.83$ & $6.02 \pm 2.23$ & $0.397^{*}$ \\
\hline hsCRP (ng/ml) & $7307.69 \pm 2670.86$ & $8765.90 \pm 2837.88$ & $0.011^{*}$ \\
\hline TSAT (\%) & $30.68 \pm 16.24$ & $29.25 \pm 14.01$ & $0.902^{\star *}$ \\
\hline TIBC (ug/dl) & $191.82 \pm 31.84$ & $199.10 \pm 41.70$ & $0.355^{*}$ \\
\hline Ferritin (ng/ml) & $889.72 \pm 659.50$ & $771.38 \pm 518.98$ & $0.607^{* *}$ \\
\hline Iron (ug/dl) & $57.94 \pm 33.98$ & $55.98 \pm 23.38$ & $0.866^{* *}$ \\
\hline PTH (Pg/ml) & $380.82 \pm 336.09$ & $384.25 \pm 294.12$ & $0.342^{* *}$ \\
\hline Albumin (mg/dl) & $3.76 \pm 0.37$ & $3.82 \pm 0.37$ & $0.413^{*}$ \\
\hline $\begin{array}{l}\text { Phosphorus } \\
\text { (mg/dl) }\end{array}$ & $4.18 \pm 1.35$ & $4.46 \pm 1.47$ & $0.340^{*}$ \\
\hline $\begin{array}{l}\text { Corrected } \\
\text { calcium (mg/dl) }\end{array}$ & $8.34 \pm 0.60$ & $8.30 \pm 0.77$ & $0.752^{*}$ \\
\hline Neutrophils & $2.24 \pm 0.99$ & $3.77 \pm 1.45$ & $<0.001^{\star *}$ \\
\hline Lymphocytes & $2.61 \pm 1.03$ & $1.68 \pm 0.65$ & $<0.001^{* *}$ \\
\hline URR (\%) & $69.69 \pm 11.13$ & $72.88 \pm 9.29$ & $0.125^{*}$ \\
\hline $\begin{array}{l}\text { Urea (pre- } \\
\text { dialysis) }(\mathrm{mg} / \mathrm{dl})\end{array}$ & $82.18 \pm 32.63$ & $90.15 \pm 32.59$ & $0.294^{* *}$ \\
\hline $\begin{array}{l}\text { Urea (post- } \\
\text { dialysis) }(\mathrm{mg} / \mathrm{dl})\end{array}$ & $23.36 \pm 10.05$ & $23.03 \pm 9.47$ & $0.887^{* *}$ \\
\hline $\begin{array}{l}\text { Cholesterol } \\
(\mathrm{mg} / \mathrm{dl})\end{array}$ & $189.03 \pm 25.93$ & $205.36 \pm 21.36$ & $0.001^{*}$ \\
\hline LDL (mg/dl) & $102.74 \pm 32.21$ & $114.38 \pm 27.82$ & $0.001^{*}$ \\
\hline TGs (mg/dl) & $161.28 \pm 28.37$ & $165.34 \pm 27.57$ & $0.479^{*}$ \\
\hline $\mathrm{Na}(\mathrm{mEq} / \mathrm{l})$ & $137.56 \pm 3.91$ & $138.44 \pm 3.41$ & $0.238^{*}$ \\
\hline $\mathrm{K}(\mathrm{mEq} / \mathrm{l})$ & $5.35 \pm 0.71$ & $5.41 \pm 0.53$ & $0.653^{*}$ \\
\hline
\end{tabular}

As shown in Table $\mathbf{2}$ and $\mathbf{3}$, by using univariate and multivariate regression analysis, NLR is considered an independent significant predictor of hSCRP as a marker of inflammation as well as PTH, LDL and $\mathrm{Na}$.

Table 3: Univariate and multivariate correlation analysis between hsCRP and different parameters. 


\begin{tabular}{|c|l|l|l|l|}
\hline \multirow{2}{*}{} & \multicolumn{2}{|l|}{ Univariate } & \multicolumn{2}{l|}{ Multivariate } \\
\cline { 2 - 5 } & $\mathbf{p}$ & OR (95\% C.I) & $\mathbf{p}$ & OR (95\% C.I) \\
\hline PTH & $\begin{array}{l}0.00 \\
8\end{array}$ & $0.998(0.996-0.999)$ & $\begin{array}{l}0.00 \\
2\end{array}$ & $0.997(0.996-0.999)$ \\
\hline $\begin{array}{l}\mathrm{N} / \mathrm{L} \\
\text { ratio }\end{array}$ & $\begin{array}{l}0.02 \\
1\end{array}$ & $1.850(1.098-3.119)$ & 0.01 & $2.302(1.208-4.388)$ \\
\hline LDL & $\begin{array}{l}0.03 \\
9\end{array}$ & $1.016(1.001-1.031)$ & 0.13 & $1.013(0.996-1.030)$ \\
\hline $\mathrm{Na}$ & $\begin{array}{l}0.02 \\
4\end{array}$ & $0.867(0.765-0.981)$ & $\begin{array}{l}0.01 \\
3\end{array}$ & $0.837(0.727-0.963)$ \\
\hline
\end{tabular}

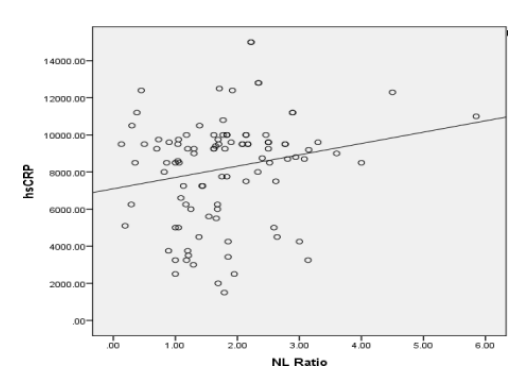

Figure1: Correlation between NLR and hsCRP.

Spearman coefficient ( $r s=0.220$ ) shows statistically significant $(p=0.028)$ positive correlation between NLR and hsCRP (Figure 1).

\section{ROC analysis of the relationship between NLR and hsCRP}

Table 4 shows that the best cut off point to detect subclinical inflammation in HD patients with NLR greater than or equal 1.54 , with sensitivity $68.25 \%$ and specificity $54 \%$, positive predictive value was 71.7 and negative predictive value was 50.0 .

Table 4: The relation between NLR and hs-CRP according to ROC analysis.

\begin{tabular}{|l|l|}
\hline & NLR \\
\hline Cut off value & $\geq 1.54$ \\
\hline Sensitivity & $68.25 \%$ \\
\hline Specificity & $54.05 \%$ \\
\hline PPV & 71.7 \\
\hline NPV & 50 \\
\hline PPV=Positive predictive value, PVT=Negative predictive value \\
\hline
\end{tabular}

It shows that NLR was positively correlated to hsCRP, using ROC curve ( $A \cup C=0.647$ ) and the best cut off point to detect subclinical inflammation in HD patients was calculated with NLR greater than or equal 1.54 , with sensitivity $68.25 \%$ and specificity $54 \%$ (Figure 2).
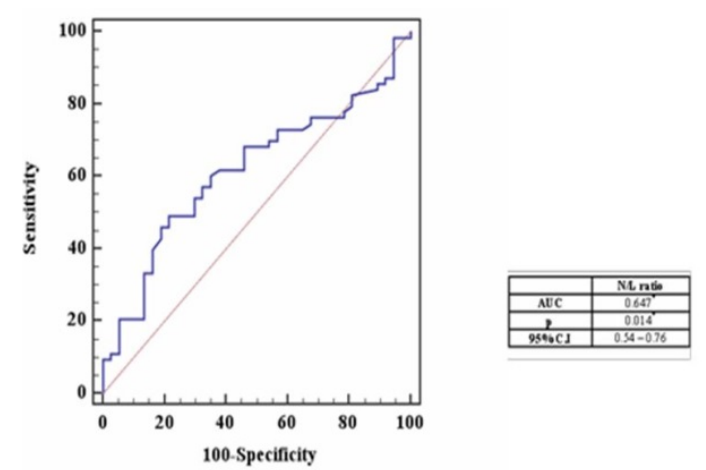

Figure 2: ROC analysis of the relationship between NLR and hsCRP.

\section{Discussion}

NLR, a novel biomarker for assessing inflammation, has been getting widely used to identify patients with various illnesses. NLR is a biomarker that integrates two WBC subtypes representing two inversely and related immune pathways. It was easily calculated from differential WBC counts, more stable for measurement than the individual WBC counts, and less affected by conditions that could change the individual cell counts. It can be calculated routinely without additional cost from the complete blood count, neutrophil-to-lymphocyte ratio (NLR) is obtained by dividing absolute neutrophil to absolute lymphocyte count [8].

This was a cross-sectional study designed to study the relation between NLR as a marker of inflammation compared to hsCRP in ESRD patients on maintenance $H D$ as well as studying the prevalence of subclinical inflammation in those patients.

It was found that sixty three (63\%) of our patients had high hsCRP (>8200 $\mathrm{ng} / \mathrm{ml}$ ) indicating presence of inflammation, despite absence of any overt signs and symptoms of inflammation. This goes in agreement with Korevaar et al. [9] that reported the prevalence of inflammation in HD patients is between $35 \%$ and $65 \%$.

Our results goes in favor with the chronic sub-inflammatory state present in ESRD, where Dai et al. [10] concluded that dialysis-related factors such as use of catheters for vascular access, poor dialyzer membrane biocompatibility, dialysate contamination, exposure to endotoxins, and back-leak of dialysate across the dialysis membrane in hemodialysis (HD) may promote a persistent, low-grade inflammatory response. Besides, other comorbidities, kidney disease per se, life style factors, genetic predisposition and, in particular, the state of uremia is of major importance as a promoter of a persistent, low-grade inflammatory response in ESRD patients [10].

Using Urea Reduction Ratio as an indicator for adequacy of hemodialysis, $83 \%$ of our patients were found to show adequate hemodialysis with URR of $65 \%$ or more.

It was expected to find an inverse relationship between adequacy of HD and prevalence of inflammation, as this 
indicates better removal of uremic toxins and inflammatory cytokines. This was demostrated by Baradaran and Nasri [11], who found inverse relation between URR and serum CRP, also, Rashid et al. [12], Borazan et al. [13] reported a negative correlation between the CRP levels and the Kt/ $\mathrm{V}$ in their study (other modality for assessing adequacy of $H D$ ) as $K$ is the dialyzer clearance of urea, $t$ for the dialysis time and $V$ for volume of distribution of urea, where, Low Kt/V less than 1.2 means dialysis inadequacy, this is associated with chronic inflammatory state resulting in high CRP levels. But surprisingly, our study found no relation between adequacy of $H D$ as demonstrated by URR and hsCRP levels.

Also in our study there is a statistically significant relation between LDL $(P=0.001)$ and cholesterol $(P=0.001)$ level and NLR and this comes in contrast to Okyay et al. who found there was no difference regarding $\mathrm{N} / \mathrm{L}$ ratio between patients with or without dyslipidemia in CKD population [14]. It was expected to find statistically significant inverse relation between serum sodium level and hsCRP $(p=0.020)$ this comes in agreement with Dekker et al. [15], who found a robust association between hyponatremia, malnutrition and inflammation. In our study we found a statistically significant positive correlation between NLR and hsCRP ( $r=0.220, p=0.028)$. These results were consistent with other studies; where Ahbap et al. [4] found same correlation with $p=0.01$, Neuen et al. [16] $(r<0.24, P<0.0023)$, also Pineault et al. [17], showed a positive correlation between CRP and NLR $(r=0.45, P<0.001)$.

This study is one of few studies to determine a cutoff point for NLR as a predictor of inflammation and assess its sensitivity and specificity.

After calculating the cutoff point for NLR that best indicates the presence of inflammation, we found that it was $\geq 1.54$ with sensitivity $68.25 \%$, specificity $54.05 \%$, with AUC: 0.647 and $\mathrm{p}=0.014$.

In contrast to our results, Ahbap et al. [4] found a cutoff point 2.82 with sensitivity $65.7 \%$ and specificity $63.3 \%$. Ahbap et al. [4] determined inflammation when hsCRP $>3 \mathrm{mg} / \mathrm{L}$ while our reference range was $\geq 8.2 \mathrm{mg} / \mathrm{L}$, difference in reference ranges might explain the different cutoff values.

While An et al. [18], reported that NLR >3.5 was associated with an increase in the risk of cardiovascular and all-cause mortality in peritoneal dialysis patents. Neuen et al. [16] reported NLR $>3.3$ was associated with increased cardiovascular mortality in hemodialysis patients.

By using univariate and multiple variate analysis in our work to test for independent predictors of hsCRP levels as an indicator for inflammation, it was found that NLR can be used as an independent predictor of hsCRP as an inflammatory marker, with statistically significant correlation $(p=0.015)$.

On further classification of the study group according to previously calculated cutoff point for NLR, it was found that $61 \%$ of our patients are considered positive for inflammation and $39 \%$ without inflammation.

Further results showed positive correlation with high significance $(p=0.002)$ between hsCRP and PTH. In addition to that, on comparing between the two groups (with and without subclinical inflammation) statistically significant correlation was found $(p=0.047)$

This comes in favor with Cheng et al. [19] stating before that accumulating evidence suggests that higher PTH levels may be associated with low-grade inflammation; adipose tissue from patients with primary hyperparathyroidism showed upregulation of inflammatory genes. Dietary-induced hyperparathyroidism in rodents led to increased serum proinflammatory cytokine production [19]. However, other conflicting data exist regarding the correlation between inflammation and PTH levels, at least in non-dialysis patients. In CKD patients, low PTH levels are associated with inflammation and oxidative stress, possible as a result of Malnutrition Inflammation Atherosclerosis (MIA) syndrome [20].

Cheng et al. [19] found positive correlation between PTH and hsCRP, on the contrary, Jaqueto et al. [20] study was not able to identify a significant correlation among PTH levels and biomarkers of inflammation and oxidative stress in chronic hemodialysis patients.

Our study didn't report any significant correlation between transferrin saturation (Tsat), serum iron, serum albumin and hsCRP neither with NLR.

This comes in contrast the results of Ahbap et al. where NLR was inversely related to Tsat [4].

Against most of previous literature that found inverse relation between hsCRP, NLR and albumin, $[16,17,21]$ there was no significant relation found between hsCRP, NLR and serum albumin (which is considered as a negative phase reactant). But this was in agreement with Ahbap et al. [4] who didn't find a relation between NLR and serum albumin.

\section{Study Limitations}

Sample size is considered relatively small and patients were collected from the same dialysis unit also. Drug history and medical therapy of the patients weren't taken into consideration in this study.

\section{Conclusion}

From our study we can conclude that NLR is an easy, simple and inexpensive method that can be used instead of hsCRP as a marker of inflammation in patients on regular HD with cutoff point $\geq 1.54$ with sensitivity $68.25 \%$, specificity $54.05 \%$.

NLR can be considered as an independent predictor of inflammation in HD patients. There was no relation between NLR and Tsat, iron, ferritin or albumin.

There is high prevalence of subclinical inflammatory state in ESRD on regular HD, where $63 \%$ were positive for inflammation according to hsCRP and $61 \%$ were positive according to NLR.

\section{Conflict of Interest}

The authors have declared that no conflict of interest exists. 


\section{Human and Animal Rights}

Not applicable.

\section{Informed Consent}

Informed consent was obtained from all individual participants included in the study.

\section{References}

1. United States Renal Data System (2009) Annual Data report 2: 269-280.

2. Sarnak MJ, Jaber BL (2000) Mortality caused by sepsis in patients with end-stage renal disease compared with the general population. Kidney Int 58: 1758-1764.

3. Yaprak M, Turan MN, Dayanan R, Akın S, Değirmen E, et al. (2016) Platelet-to-lymphocyte ratio predicts mortality better than neutrophil-to-lymphocyte ratio in hemodialysis patients. Int Urol Nephrol 48: 1343-1348.

4. Ahbap E, Sakaci T, Kara E, Sahutoglu T, Koc Y, et al. (2016) Neutrophil-to-lymphocyte ratio and platelet- tolymphocyte ratio in evaluation of inflammation in end-stage renal disease. Clin Nephrol 85: 199-208.

5. Gürağaç A ,Demirer Z (2016) The neutrophil-to-lymphocyte ratio in clinical Practice. Can Urol Assoc J 10: 141.

6. Ouellet G, Malhotra R, Penne L, Usvya L, Levin NW, et al. (2016) Neutrophil-lymphocyte ratio as a novel predictor of survival in chronic hemodialysis patients. Clin Nephrol 85: 191-198.

7. Brunelli S (2017) The Dialysis Prescription. In Nissenson AR, Fine RN (eds) Handbook of Dialysis Therapy (5th edn.) Elsevier 274-280.

8. Han Li, Xiangxue Lu, Ruifang Xiong, and Shixiang Wang (2017) High Neutrophil-to-Lymphocyte Ratio Predicts Cardiovascular Mortality in Chronic Hemodialysis Patients. Mediators Inflamm.

9. Korevaar JC, , Dekker FW, Boeschoten EW, Krediet RT, et al. (2004) Effect of an increase in C-reactive protein level during a hemodialysis session on mortality. J Am Soc Nephrol 15: 2916-2922.

10. Dai L, Golembiewska E, Lindholm B, Stenvinkel P (2017) End-stage renal disease, inflammation and cardiovascular outcomes. In: Expanded Hemodialysis. Karger 191: 32-43.
11. Nasri H (2005) Association of Serum C - reactive protein (CRP) with Some Nutritional Parameters of Maintenance Hemodialysis Patients. Bratisl Lek Listy 106: 390-395.

12. Rashid H, Ru, Au (2015) Comparison of C-reactive protein levels with delivered dose of $\mathrm{Kt} / \mathrm{V}$ in patients with end-stage renal disease on maintenance hemodialysis. Saudi J Kidney Dis Transpl 26: 692-696.

13. Borazan A, Aydemir S, Sert M, Yilmaz A (2004) The effects of hemodialysis and peritoneal dialysis on serum homocysteine and C-reactive protein levels. Mediators Inflamm 13: 361-364.

14. Okyay GU, Inal S, Oneç K, Er RE, Paşaoğlu O, et al. (2013) Neutrophil to lymphocyte ratio in evaluation of inflammation in patients with chronic kidney disease. Ren Fail 35: 29-36.

15. Dekker MJE, Marcelli D, Canaud B, Konings CJA, Leunissen KM, et al. (2016) Unraveling the relationship between mortality, hyponatremia, inflammation and malnutrition in hemodialysis patients: results from the international MONDO initiative. Eur J Clin Nutr 70: 779-784.

16. Neuen BL, Leather N, Greenwood AM, Gunnarsson R, Cho Y (2016) Neutrophil-lymphocyte ratio predicts cardiovascular and all-cause mortality in hemodialysis patients. Ren Fail 38: 70-76.

17. Pineault J, Lamarche C, Bell R, Lafrance JP, Ouellet G, et al. (2017) Association of Neutrophil-to-Lymphocyte Ratio with Inflammation and Erythropoietin Resistance in Chronic Dialysis Patients. Can J Kidney Health Dis 4.

18. An X, Mao HP, Wei X, Chen JH, Yang X, et al. (2012) Elevated neutrophil to lymphocyte ratio predicts overall and cardiovascular mortality in maintenance peritoneal dialysis patients. Int Urol Nephrol 44: 1521-1528.

19. Cheng SP, Liu CL, Liu TP, Hsu YC, Lee JJ (2014) Association between Parathyroid Hormone Levels and Inflammatory Markers among US Adults. Mediators Inflamm 1-8.

20. Jaqueto M, Delfino VDA, Bortolasci CC, Barbosa DS, Morimoto HK, Frange RFN, et al. (2016) Are PTH levels related to oxidative stress and inflammation in chronic kidney disease patients on hemodialysis? J Bras Nefrol 38: 288-295.

21. Turkmen K, Guney I, Yerlikaya FH, Tonbul HZ (2012) The Relationship Between Neutrophil-to-Lymphocyte Ratio and Inflammation in End- Stage Renal Disease Patients. Ren Fail 34: 155-159. 